\title{
Laparoscopic versus vaginal approaches in closure of vaginal vault in laparoscopic hysterectomy
}

\section{Abstract}

Objective: To make a comparison between the laparoscopic and vaginal approaches in closure of vaginal vault in laparoscopic hysterectomy

Material and methods: A prospective randomized controlled study was made on 80 women who were subjected to total laparoscopic hysterectomy for benign lesions in Helwan University Hospitals and Algezeera Hospital, Egypt.

Patients were randomized equally into 2 groups; I the first group vault closure was made laparoscopically and in the second group it was made vaginally in the period from June 2016 till November 2018.

Conclusion: Vault closure using laparoscopic approach was better than vaginal approach regarding postoperative pain and postoperative complications
Volume 10 Issue I - 2019

\author{
Ahmed Hassan Sayed Ahmed \\ Lecturer of Obstetrics and Gynecology, Helwan University, \\ Egypt
}

Correspondence: Ahmed Hassan Sayed Ahmed, Lecturer of Obstetrics and Gynecology, Helwan University, Cairo, Egypt, Tel 00201226223822, Email dra7mad7asan@icloud.com

Received: January 28, 2019 | Published: February 18, 2019

Keywords: vault, laparoscopic, vaginal, hysterectomy, approach

\section{Introduction}

Hysterectomy is considered as a common operation in Gynecology.

Hysterectomy could be made by vaginally, laparoscopically or abdominally. The American Congress of Obstetricians and Gynecologist advises the use of a minimally invasive technique for the sake of women and to decrease hospital stay and costs. ${ }^{2}$

Laparoscopic hysterectomy (LH) is a minimally invasive operation that could be made when vaginal hysterectomy is not accessible due to anatomical problems. ${ }^{3}$

Vaginal vault dehiscence is a partial or total division of the edges of the vault of vaginal with or without bowel herniation This complication is more common with LH when compared to both vaginal or abdominal routes..$^{4,5}$

\section{Materials and methods}

Eighty two women who are candidate for laparoscopic total hysterectomy was done during the period of June 2017 to November 2018 in Helwan University Hospitals and Algezeera Hospital, Egypt. Patients were selected with the common criteria of benign gynecological disorders for hysterectomy. The indications varied from chronic pelvic in ammatory diseases (PID), dysfunctional uterine bleeding, adenomyosis, endometriosis, broid, endometrial hyperplasia, benign ovarian cyst.

All women participated in this study signed an informed consent The same operative and anesthetic techniques were made in all women. All ladies were exposed to the same technique of laparoscopy and same preparation.

The technique of approximation of the vault was made either with laparoscopic method or through vaginal method with the use of vicryl 1 to see the difference between the two methods.

Laparoscopic approach was done with continuous suturing of the vault with adequate homeostasis.

Eighty two ladies were promptly aware about details of maneuver. Advancement in surgical techniques allows us to enormously reach to the best steps in endoscopy that favors better outcomes for the sake of the ladies who suffered from gynecological abnormalities.

Various trials were seeked in order to analyze changes in occluding vault so this work sought this methodology by following the course of events for women, we achieved the goal of the study.

\section{Results}

The present study was a prospective randomized controlled study which was made on 80 women who were subjected to total laparoscopic hysterectomy for benign lesions in Helwan University Hospitals and Algezeera Hospital, Egypt.

Patients were randomized equally into 2 groups; I the first group vault closure was made laparoscopically and in the second group it was made vaginally in the period from June 2016 till November 2018.

The indications varied from chronic pelvic inflammatory diseases (PID), dysfunctional uterine bleeding, adenomyosis, endometriosis, fibroid, endometrial hyperplasia, benign ovarian cyst.

Our aim was to make a comparison between the laparoscopic and vaginal approaches in closure of vaginal vault in laparoscopic hysterectomy.

In the present study, there was no statistical difference between both groups as regard age, age at menopause and duration of menopause as mentioned in Table 1.

Table I shows a descriptive data of the study

\begin{tabular}{lllll} 
& Mean \pm SD & Median & Minimum & Maximum \\
\hline $\begin{array}{l}\text { Age (years) } \\
\begin{array}{l}\text { Menopause age } \\
\text { (years) }\end{array}\end{array}$ & $56.44 \pm 4.94$ & 55 & 49 & 67 \\
$\begin{array}{l}\text { Duration of } \\
\text { menopause (years) }\end{array}$ & $5.69 \pm 4.62$ & 4.5 & 1.5 & 12 \\
$\begin{array}{l}\text { Body weight (Kg) } \\
\text { Height (M) }\end{array}$ & $90.95 \pm 16.80$ & 90 & 62 & 128 \\
BMI & $34.11 \pm 7.19$ & 31.5 & 23 & 46 \\
\hline
\end{tabular}




\section{Discussion}

In a previous study made to compare laparoscopic versus vaginal approach, the mean time for laparoscopic approach and vaginal approach was 77.0 and 88.5 minutes respectively.

Laparoscopic route required about 11 minutes less than when it is compared to vaginal method and it was statically significant $(p<0.00){ }^{6}$

In the current research, in both groups of the study there was no statistical difference as regard BMI, weight and height as mentioned in Table 1.

In accordance with our study, a research made by Jong Ha Hwang et al. showed more operative time with the vaginal technique. ${ }^{7}$

The average time for total laparoscopic hysterectomy ranges from 76 to 192 minutes. $^{7-9}$

In a previous study made by Kanupriya Singh, in laparoscopic technique of vaginal closure, the mean post operative vaginal length was $9.3 \mathrm{~cm}$ while it was $8.3 \mathrm{~cm}$ in vaginal method. The difference was statically significant $\mathrm{p}<0.00{ }^{6}$

In laparoscopic technique during vault suturing, the uterosacral ligaments are clearly seen and involved in the ligature and this leads to proper vault suspension when compared to vaginal technique in which this delineation is not always feasible. ${ }^{8}$

A previous study made by Kanupriya Singh showed post-operative complications rate was $58.6 \%$, But $28.5 \%$ women had post operative complications in laparoscopic technique of vault suturing as compared to $88.5 \%$ in vaginal way of vault closure. ${ }^{6}$

In the present study, postoperative pain was less in the laparoscopic approach than in the vaginal approach with a statistically significant difference with a P value 0.043 .

In contrary to the present study, Jong Ha Hwang et al. ${ }^{6}$ revealed that there was no statistically significant difference in complications that occurred postoperatively in laparoscopic method in comparison to vaginal method of vault suturing. ${ }^{7}$

In our study, although the postoperative hemorrhage was more in the laparoscopic method than in vaginal method but the difference wasn't statistically significant.

In a study made by Kanupriya Singh; women in vaginal method had significant pain on routine analgesia, they were given tramadol, whereas in laparoscopic method only 4 women used higher analgesia. This is explained by in vaginal technique there is more pulling of uterosacral ligaments and more vaginal tissues are included. ${ }^{6}$

In agreement to the present study, Kanupriya Singh found that in the laparoscopic technique, sutures are inverted and not subjected to vaginal bacteria thus there is lesser possibility of post operative vault infection and less possibility to vault dehiscence. ${ }^{6}$

Previous study by Uccella et al. ${ }^{10}$ revealed that closing the vaginal vault by laparoscopic way in the total laparoscopic hysterectomy is accompanied with a decrease in vaginal complications, vault dehiscence or hematoma, postoperative infection. ${ }^{10}$

Kumar and Lekkala found that Laparoscopic hysterectomies is accompanied with less blood loss, less hospital stay and less period of recovery a decrease in wound infection postoperative pain, and shorter operative time. ${ }^{11}$
Moreover, in the current research, the post-operative complications as regard postoperative infection, vault prolapsed and vault dehescince were less in the laparoscopic maneuver for vault closure than in the vaginal maneuver but the difference wasn't statistically significant with a $\mathrm{P}$ value $0.494,0.57$ and 0.494 respectively as mentioned in Table 2.

Table 2 postoperative complications

\begin{tabular}{llll}
\hline Complications & $\begin{array}{l}\text { Vault } \\
\text { closure route } \\
\text { laparoscopic } \\
\text { number (41) }\end{array}$ & $\begin{array}{l}\text { Vault } \\
\text { closure rout } \\
\text { vaginal } \\
\text { number (41) }\end{array}$ & P value \\
\hline Hemorrhage & $4(9.8 \%)$ & $1(2.4 \%)$ & 0.359 \\
infection of the vault & $0(0 \%)$ & $2(4.8 \%)$ & 0.494 \\
prolapse of the vault & $1(2.4 \%)$ & $7(17.1 \%)$ & 0.057 \\
Postoperative pain & $2(4.8 \%)$ & $8(19.5 \%)$ & 0.043 \\
$\begin{array}{l}\text { Dehiscence of the vault } \\
\text { Vaginal spotting }\end{array}$ & $0(0 \%)$ & $2(4.8 \%)$ & 0.494 \\
Total & $3(7.3 \%)$ & $5(12.2 \%)$ & 0.712 \\
$\begin{array}{l}\text { Operative time for vault } \\
\text { closure }\end{array}$ & $3.8(1.2)$ & $25(61 \%)$ & 0.014 \\
Postoperative hospital stay & $1.1(0.4)$ & $5.5(1.4)$ & 0.023 \\
\hline
\end{tabular}

In both techniques posterior vagina is not transected, so pelvic innervations are unaffected, so the possibility of vault prolapse is less.

\section{Conclusion}

The post-operative complications after laparoscopic hysterectomy in the form of pain was significantly lower in the laparoscopic approach as compared to vaginal approach suturing for vault closure. While other postoperative complications (vault infection, vault prolapse, dehiscence) were less in laparoscopic than vaginal route but the difference wasn't statistically significant.

We concluded that laparoscopic technique of closing vault is better than vaginal route specially as regard postoperative pain.

\section{Acknowledgments}

None.

\section{Conflicts of interest}

The authors declare that there is no conflict of interest regarding the publication of this paper.

\section{References}

1. Cong L, Li C, Wei B, et al. V-Loc ${ }^{\mathrm{TM}} 180$ suture in total laparoscopic hysterectomy: a retrospective study comparing Polysorb to barbed suture used for vaginal cuff closure. Eur J Obstet Gynecol Reprod Biol. 2016;207:18-22.

2. ACOG Committee Opinion No. 444: choosing the route of hysterectomy for benign disease. Obstet Gynecol. 2009;114(5):1156-1158.

3. Reich H, Decaprio J, Mcglynn F. Laparoscopic Hysterectomy. Journal of Gynecologic Surgery. 1989;5(2):213-216. 
4. Fanning J, Kesterson J, Davies M, et al. Effects of electrosurgery and vaginal closure technique on postoperative vaginal cuff dehiscence. JSLS. 2013;17(3):414-417.

5. Hur HC, Guido RS, Mansuria SM, et al. Incidence and patien characteristics of vaginal cuff dehiscence after different modes of hysterectomies. J Minim Invasive Gynecol. 2007;14(3):311-317.

6. Kanupriya S, Bhavit S, Vipul P, et al. Vaginal vault closure techniques in total laparoscopic hysterectomy: a comparison between laparoscopic route vault suturing and vaginal route. National Journal of Community Medicine. 2011;2(2):289-292.

7. Hwang JH, Lee JK, Lee NW, et al. Vaginal Cuff Closure: A Comparison between the Vaginal Route and Laparoscopic Suture in Patients Undergoing Total Laparoscopic Hysterectomy. Gynecol Obstet Invest. 2011;71(3):163-169.
8. Ostrzenski A. Laparoscopic total abdominal hysterectomy by suturing technique, with no transvaginal surgical approach: a review of 276 cases. Int J Gynaecol Obstet. 1996;55(3):247-257.

9. Einarsson JI, Suzuki Y. Total laparoscopic hysterectomy: 10 steps towards a successful procedure. Rev Obstet Gynecol. 2009;2(1):57-64.

10. Uccella S, Malzoni M, Cromi A, et al. Laparoscopic vs transvaginal cuff closure after total laparoscopic hysterectomy: a randomized trial by the Italian Society of Gynecologic Endoscopy. Am J Obstet Gynecol. 2018;218(5):500.e1-500.e13.

11. Kumar G, Lekkala S. Complications after a total laparoscopic hysterectomy: a study in tertiary care unit in Telangana, India. Int Surg J. 2016:1141-1145. 